\title{
вM] Global Health Migrants caught between tides and politics in the Mediterranean: an imperative for search and rescue at sea?
}

\author{
Federica Zamatto, ${ }^{1}$ Stefano Argenziano, ${ }^{1}$ Jovana Arsenijevic, ${ }^{2}$ Aurelie Ponthieu, ${ }^{3}$ \\ Marco Bertotto, ${ }^{1}$ Francesco Di Donna, ${ }^{1}$ Anthony D Harries, ${ }^{4,5}$ Rony Zachariah ${ }^{2}$
}

To cite: Zamatto $\mathrm{F}$, Argenziano S, Arsenijevic J, et al. Migrants caught between tides and politics in the Mediterranean: an imperative for search and rescue at sea?BMJ Glob Health 2017;2:e000450. doi:10.1136/ bmjgh-2017-000450

Handling editor Seye Abimbola

Received 30 June 2017 Revised 23 August 2017 Accepted 24 August 2017

\section{(a) CrossMark}

${ }^{1}$ Operations and Medical Department, Médecins Sans Frontières, Brussels Operational Centre, Rome, Italy ${ }^{2}$ Operational Research Unit (LuxOR), Médecins Sans Frontières, Brussels Operational Centre, Luxembourg City, Luxembourg

${ }^{3}$ Analysis and Advocacy Unit, Médecins Sans Frontières, Brussels Operational Centre Brussels, Belgium

${ }^{4}$ Center for Operational Research, International Union Against Tuberculosis and Lung Disease, Paris, France

${ }^{5}$ London School of Hygiene and Tropical Medicine, London, UK

\section{Correspondence to} Dr Rony Zachariah; rony.zachariah@brussels.msf org
It was in the 1980s when the first bodies of migrants and refugees from the global south were washed up on European shores. ${ }^{1}$ In the absence of safe and legal alternatives, people continue to embark on perilous sea journeys for a myriad of reasons; they are fleeing persecution, violence and poverty and seeking freedom, safety and a better life in Europe. Thousands continue to die in the Central Mediterranean Sea which has proved to be the most dangerous route. ${ }^{2}$

The greatly mediatised Lampedusa shipwreck of 3 October 2013 when 368 migrants and refugees died off the Italian coast is credited with the launch of an Italian state-led mission 'Mare Nostrum'. ${ }^{4}$ The operation had an explicit humanitarian objective and involved identifying boats in distress and then rescuing people-a proactive 'Search and Rescue (SAR)' operation that operated close to the Libyan coast. Significant human resources, military rescue assets as well as financial means were placed at its disposal costing the Italian state a total of $€ 9$ million per month. Thanks to Mare Nostrum, at least 150000 migrants and refugees were rescued. ${ }^{4}$ Mare Nostrum ended in October 2014, largely because of a lack of European Union support and because it was considered a pull factor for migrants and refugees to Europe. It was superseded by Frontex's 'Operation Triton,' whose mandate was primarily to secure the European Union's external borders. It was not designed as SAR mission. Sea rescues were thus relegated to only what is routinely demanded by maritime obligations. Unlike Mare Nostrum, Triton operated close to the Italian coast (a much smaller rescue area compared with Mare Nostrum) and had far less rescue assets placed at its disposition by the European Union-costing $€ 4.6$ million per month. ${ }^{5}$

This retreat from proactive 'SAR' operations by the European Union tacitly left

\section{Summary box}

In the late 2014, owing to lack of European Union support, the Italian state retreated from their Mare Nostrum - a proactive 'Search and Rescue' (SAR) operation in the central Mediterranean leaving thousands to die at sea.

- Humanitarian Non-Governmental Organisations (NGOs) including Médecins Sans Frontières (MSF) stepped in to fill this gap but have been recently accused of being a 'pull factor' for migrants and refugees and being a cause for deterioration in maritime safety by increasing deaths at sea.

- Contrary to the pull factor hypothesis, the number of sea arrivals during the NGO involvement period (with proactive SAR operations) was lower than during equivalent prior periods. Mortality rates were also substantially lower during the NGO period compared with similar prior periods.

- These findings strongly support arguments that SAR operations by humanitarian NGOs reduce mortality risks and have little or no effect on the number of arrivals.

thousands of people to drown at sea and was criticised for a ninefold increase in deaths between 2014 and 2015. ${ }^{16}$ On 25 April 2015, the President of the European Commission, Jean-Claude Juncker, summarised it well

"It was a serious mistake to bring Mare

Nostrum operations to an end. It cost human lives". ${ }^{7}$

As a buffer response, Médecins Sans Frontières (MSF) launched its own SAR operations with medically equipped ships having a capacity of carrying 400 to 700 rescued people. ${ }^{8}$ MSF's objective was simple: try to save human lives in full respect of its independent mandate as a medical-humanitarian organisation. $^{9}$

In 2016, MSF teams, working on the Bourbon Argos rescue ship in coordination with the Maritime Rescue Coordination Centre in Rome, rescued 10415 people. During the same year, a total of 46882 
individuals were rescued ( 1 in 5 of all rescues at sea in 2016) by a humanitarian flotilla belonging to Non-Governmental Organisations (NGOs) which included several organisations besides MSF.

It is alleged by some politicians and officials in EU member states (Italy, Belgium and Austria) and some members of the Italian Judiciary that by providing SAR service, Mare Nostrum and now humanitarian NGOs have made the journey easier and safer and therefore encourage migrants and refugees to take to sea-a 'pull factor' for irregular migration. They argue that these NGOs are acting as a 'bridge to Europe'. By operating their rescue boats close to the Libyan coast, NGOs are also accused of deteriorating maritime safety by pulling people to sea and increasing the risk of dying. ${ }^{10}$

These are baseless claims that are not substantiated with data. A recent assessment of the 'pull factor' hypothesis compared the Triton-only period with relatively lower levels of SAR operations (November 2014May 2015) to similar periods before (during Mare Nostrum) and after (when humanitarian NGOs joined the SAR flotilla). The latter two periods had comparatively higher levels of SAR operations. ${ }^{2}$ If SAR operations during Mare Nostrum and with humanitarian NGOs did encourage more arrivals and entail increased risks for those taking to sea, we would expect more arrivals and higher mortality risks in these two periods compared with the Triton-only period. In fact, the findings indicate the contrary. The number of arrivals in the Triton period was higher (63 637) compared with the Mare Nostrum period (45 446) and the period that involved NGOs (60 738). The pull factor argument fails on the existing evidence. In addition, it ignores the reality of the complexity of migratory movements. Naively insisting that migrants take to sea simply because of pull factors is based on a fundamental misconception on how these movements work.

Mortality rates were also substantially higher during Triton (27.9 deaths / 1000 arrivals) than in the respective Mare Nostrum (20.9 deaths/1000 arrivals) and humanitarian NGO periods (19.9 deaths/1000 arrivals). ${ }^{2}$ In combination, these findings strongly support arguments that SAR operations reduce mortality risks and have little or no effect on the number of arrivals. ${ }^{2}$ In effect, the humanitarian NGO period through reduced deaths is associated with a $29 \%$ improvement in maritime safety compared with the Triton period. Without humanitarian NGO boats, the annual numbers of deaths and people missing at sea would thus have been higher. Nevertheless, the fact that 5143 deaths at sea were still reported in 2016 indicates that there are persisting gaps in mitigating risks of death associated with desperate sea journeys. ${ }^{11}$

The European Union's naval force in the Mediterranean has also recognised that migrant vessels are grossly overcrowded and should be considered in distress from the moment they launch. ${ }^{12-14}$ Having rescue boats closer to the Libyan coast thus responds to what could be considered a humanitarian imperative to prevent deaths.

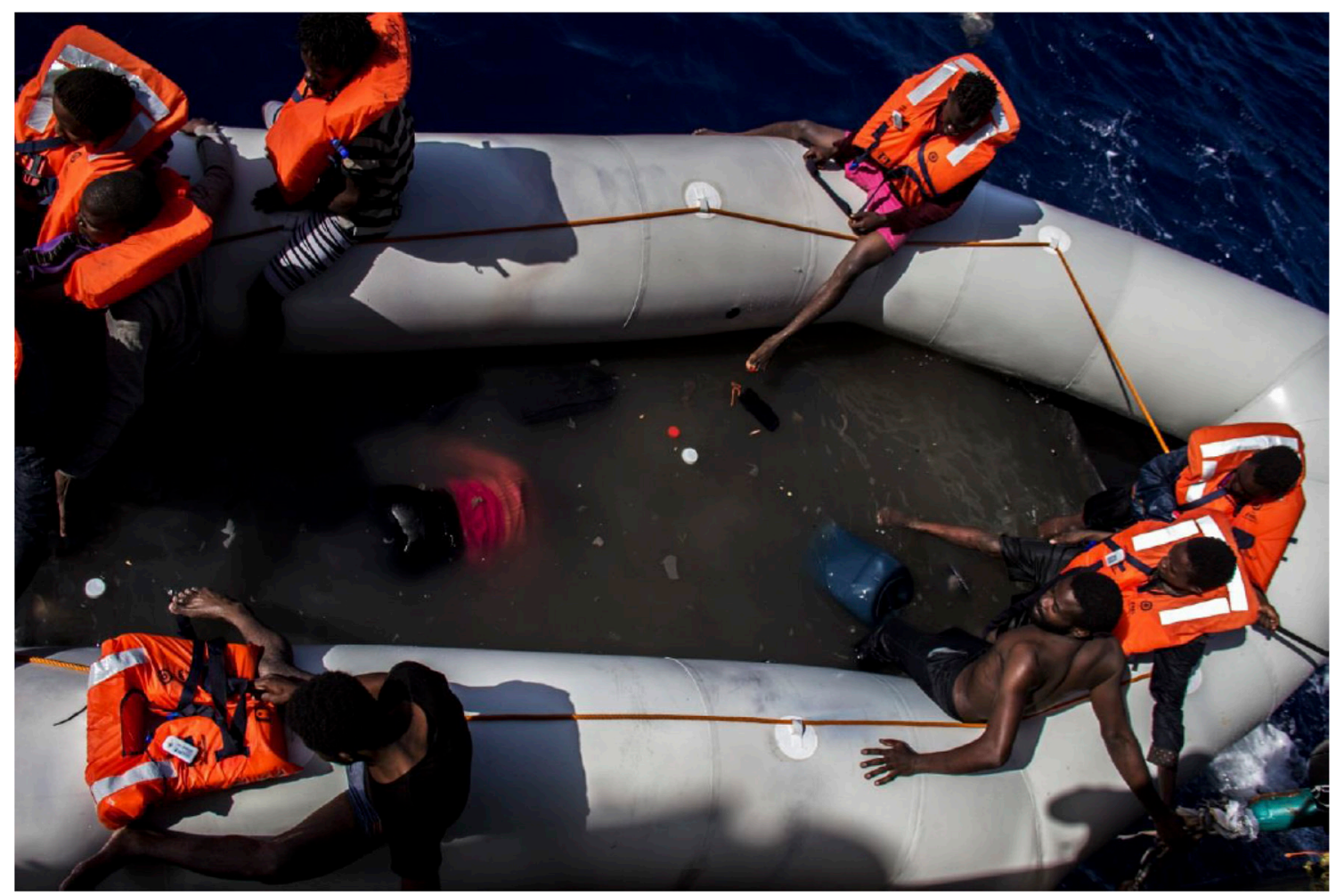

Figure 1 People waiting to be rescued, dead bodies and leaked fuel containers during a Médecins Sans Frontières Search and Rescue operation in the Mediterranean Sea. (107 were rescued with 23 having sustained chemical burns). 
In addition to contributing to reduced mortality, in 2016, MSF rescue boats also offered on-deck emergency medical care to 1670 individuals including pregnant women and children. Among those needing urgent attention were 84 individuals with fuel burns. A fuel burn is a 'chemical burn' which occurs when gasoline mixes with salty seawater and then comes in contact with the human skin. The mix happens when containers carrying gasoline leak, get knocked over or spill when frantic attempts are made to dump gasoline in order to bail out a sinking dinghy or boat (figure 1). The skin that comes into contact with the erosive mixture rapidly burns. Those crammed at the centre of the vessel are most vulnerable, as higher levels of onboard water enhance wider skin exposure to the mixture. Picture a potato peeler applied to someone's thighs and buttocks plus the groins and genitals. That's what it looks like. ${ }^{15}$ Of the 84 individuals seen with firstto third-degree burns by MSF, there were 46 women, 3 of whom were pregnant, and 19 were minors. Seven individuals having over $20 \%$ of their body surface burned had to be evacuated by helicopters or speedboats to Italy for specialised care. If they survived, they will still end up with physical scarring for life.

In summary, humanitarian rescuers are thus not 'the cause' but a desperate response to an ongoing human tragedy. ${ }^{16}$ A human tragedy which, at best, reflects Europe's scathing failure to manage migratory flows in a humane and effective manner. ${ }^{17}$ At worst, it is tantamount to deliberate 'non-assistance' to people drowning at sea. The alternative view that these are highly vulnerable people whose human rights are not being respected is not considered. Furthermore, migration by sea is not a European-only phenomenon and exists in other regions including the Gulf of Aden, the Caribbean and the Asia Pacific region. People taking these dangerous sea routes are met with harsh response by states. The humanitarian imperative to save lives and grant international protection is often replaced by deterrence and punishment. ${ }^{17} 18$ Australia is one telling example of such an approach. It imposes systematic detention in offshore facilities on asylum seekers trying to reach its territory by boat in offshore facilities based on the political argument that it is dangerous to attempt the sea crossings, and this should therefore be strongly discouraged. ${ }^{19}$

Our unequivocal call to Europe and the international community is clear. Introduce more rescue assets that will enable a higher level of proactive SAR operations that could save more lives. Europe also needs to give up deterrence-based policies and instead introduce safe and legal channels for migration as a primary solution to smuggling and dangerous sea crossings. ${ }^{18}$

In the meantime, for humanitarian NGOs such as MSF, there is a valid humanitarian imperative to save lives through 'SAR' as it involves respecting international legal obligations, but more fundamentally, it is about upholding fundamental human values.
Contributors All authors were involved with article conception and design. JA and RZ did the initial data analysis which was critically reviewed by FZ and all coauthors. RZ wrote the first draft of the manuscript and led the revisions which were also critically reviewed by all coauthors. All authors have seen and agreed with the final version of the manuscript.

Competing interests None declared.

Provenance and peer review Not commissioned; externally peer reviewed.

Data sharing statement The data in the study is available from the corresponding author on specific request subject to MSF's data sharing policy (http://www.msf. org/sites/msf.org/files/msf_data_sharing_policy_final_061213.pdf) by contacting data.sharing@msf.org.

Open Access This is an Open Access article distributed in accordance with the Creative Commons Attribution Non Commercial (CC BY-NC 4.0) license, which permits others to distribute, remix, adapt, build upon this work non-commercially, and license their derivative works on different terms, provided the original work is properly cited and the use is non-commercial. See: http://creativecommons.org/ licenses/by-nc/4.0/

(c) Article author(s) (or their employer(s) unless otherwise stated in the text of the article) 2017. All rights reserved. No commercial use is permitted unless otherwise expressly granted.

\section{REFERENCES}

1. Heller C, Pezzali L, Rescue D. The lethal effects of the EU's policies of non-assistance. https://deathbyrescue.org/ (accessed 10 May 2017).

2. Steinhilper E, Gruijters R. Border deaths in the Mediterranean: what we can learn from the latest data. https://www.law.ox.ac. uk/research-subject-groups/centre-criminology/centrebordercriminologies/blog/2017/03/border-deaths (accessed 14 Jul 2017).

3. Guardian T. Lampedusa shipwreck: Italy to hold state funeral for drowned migrants, 2013. https://www.theguardian.com/world/2013/ oct/09/lampedusa-shipwreck-italy-state-funeral-migrants (accessed 10 May 2017).

4. MOD. Italian Ministry of Defence. Mare Nostrum Operation, 2013. http://www.marina.difesa.it/EN/operations/Pagine/MareNostrum. aspx (accessed 10 May 2017).

5. EU. Frontex Joint Operation 'Triton'-Concerted efforts to manage migration in the Central Mediterranean, 2014. http://europa.eu/rapid/ press-release_MEMO-14-566_en.htm (accessed 10 May 2017).

6. Guardian T. 700 migrants feared dead in Mediterranean shipwreck. 2015 https://www.theguardian.com/world/2015/apr/19/700migrants-feared-dead-mediterranean-shipwreck-worst-yet (accessed 12 May 2017).

7. EU. Speech by President Jean-Claude Juncker at the debate in the European Parliament on the conclusions of the Special European Council on: 'tackling the migration crisis'. 2015 http://europa.eu/ rapid/press-release_SPEECH-15-4896_en.htm (accessed 10 May 2017).

8. Bourbon. Bourbon Argos: Mediterranean rescue operations. 2017 http://www.bourbonoffshore.com/en/offshore/bourbon-argosmediterranean-rescue-operations (accessed 10 May 2017).

9. Kentilelenis AE, Shriwise A. International organisations and migrant health in Europe. : Public health reviews, 2016:vol 37: 1-20.

10. Xinhua. Controversy over migrant-rescue NGOs heats up in Italy, 2017. http://news.xinhuanet.com/english/2017-05/03/c_136252013. htm (accessed 10 May 2017).

11. IOM. Missing migrants: tracking deaths along migratory routes. https://missingmigrants.iom.int/mediterranean (accessed 14 July 2017).

12. EU. EuNavForMed operation (Ops SOPHIA). 2016. WikiLeaks release https://wikileaks.org/eu-military-refugees/EEAS/EEAS-2016-126 (accessed 17 Feb 2016).

13. Med E. Article 1, Council Decision $2015 / 778$ of 18 May 2015 on a European Union military operation in the Southern Central Mediterranean (EUNAVFOR MED). (accessed 19 May 2015).

14. SOLAS. SOLAS Convention. https://en.wikipedia.org/wiki/SOLAS_ Convention

15. Sarah G. Fuel Burns. 2017 http://blogs.msf.org/en/staff/blogs/ moving-stories/fuel-burns (accessed 10 May 2017).

16. Ponthieu A. Bounties not bodies: smugglers profit from sea rescues though no clear alternative. 2017 http://msf-analysis.org/ bounties-not-bodies-smugglers-profit-sea-rescues-though-no-clearalternative-available/ (accessed 10th May 2017). 
17. Heller C, Pezzani L. Blaming the rescuers, criminalizing solidarity, re-inforcing deterrence. 2017. accessed 13 Jun 2017 https:// blamingtherescuers.org.

18. Turner S. Refugee blues: a UK and European perspective. Eur J Psychotraumatol 2015;6:29328.
19. Guardian T. Offshore detention: Australia's recent immigration history a 'human rights catastrophe'. https://www.theguardian.com/ australia-news/2016/nov/13/offshore-detention-nauru-immigrationhistory-human-rights (accessed 16 July 2017). 